\title{
Developing Languages to Face Challenges of Globalization and Clash of Civilizations: Arabic Language as an Example
}

\author{
Ghassan I. Alfataftah ${ }^{1} \&$ Amani G. Jarrar ${ }^{2}$ \\ ${ }^{1}$ Faculty of Arts, Philadelphia University, Philadelphia, USA \\ ${ }^{2}$ Department of Development Studies, Faculty of Arts, Philadelphia University, Philadelphia, USA \\ Correspondence: Amani G. Jarrar, Department of Development Studies, Faculty of Arts, Philadelphia University, \\ Philadelphia, USA.
}

$\begin{array}{lr}\text { Received: March 2, } 2018 \quad \text { Accepted: March 26, } 2018 \quad \text { Online Published: May 15, } 2018 \\ \text { doi:10.5539/jel.v7n4p247 } & \text { URL: https://doi.org/10.5539/jel.v7n4p247 }\end{array}$

\begin{abstract}
This study aimed at questioning the ability of Arabic language to assimilate the different cultures facing the cultural challenges due to globalization and clash of civilizations. The study examined the ability of Arabic language to cope with global developments and cultural changes. The researchers adopted the historical, inductive and deductive methodologies. The study concluded that Arabic language curricula should be directed towards focusing on communication functions in order to promote Arabic language to be capable of dealing with contemporary and practical cultural and developmental problems.
\end{abstract}

Keywords: globalization, clash of civilizations, Arabic language, development

\section{Introduction}

Whether the German philosopher Herder (1744-1803) was the first to recognize the primacy of language on the mind (Rosenthal \& Yudin, 1985); it is certain that any person needs language first; so that he can think. The relationship between language and thinking become controversial; so that nations think as they speak, and speak as they think, so that mechanisms and patterns of thinking in their languages and methods and levels of expression to these mechanisms and patterns become part of them (Herder, 2002). Which automatically raises the absurdity of the separation between words and meanings, and makes it a purely visual illusion that justifies the naive conception of language as a mere means or a container of subjects, cultures and ideas. (Selsam, 1950)

Within the last thirty years, significant cultural, economic and political changes have occurred all across the globe. And as physical and geographical boundaries are shrinking, cross-cultural interaction is at its highest degree in human history (Zakaria, 2011).

Cross-cultural interaction and cultural changes have also affected the education processes and practices of language, as multilingualism has become a common phenomenon all around the world. However, a number of languages including Arabic, Bengali, English, French, Hindi, Malay, Mandarin, Portuguese, Russian, and Spanish are languages of wider communication in the world. These languages are also often spoken and well spread (Spolsky, 2009).

If there is a nation to which Herder's statement applies to a large extent, it is the Arab nation, not because it thinks as it speaks and speaks as it thinks, on the other hand, some critics criticized the Arabic language as having that duality dilemma, making difference between what is thought and what is articulated, especially when dealing with linguistic metaphors. But others, like Arabs, think highly of it, considering it as a language as the carrier of its cultural message to the world (Al-Jabri, 1985), and it is also considered as a language of codes; it is the project of transition from the stage of oral culture to the stage of biblical culture on a later stage (Stadlbauer, 2010).

The research in the codification and documentation in the Arabic language leads to the dangerous role played by the (field of semantics) and then the (term defining field), as these are in fact the two titles that can summarize the fact of the cosmic rise of the Arab-Islamic culture, and on the one hand, the linkages between branches of Arab-Islamic culture, which caused the phenomenon of rejecting diversity in the Arab-Islamic culture. 


\section{Problem Statement}

The challenges of globalization and the clash of civilizations have clear implications on languages in general, and on Arabic in particular, especially when thinking of it in terms of Islamic thought and culture. Arabic language is to be studied as a means of cultural communication, promoting it in its ability as a language to absorb the cultural changes that result from globalization and clash of civilization, and thus affecting its implications for human societies coexistence. Hence, the problem of this research is stated in ways of making the Arabic language capable of coping with the challenges due to globalization and clash of civilizations, making it able to cope with global developments and cultural changes.

\section{Research Methodology}

The researchers adopted the historical methodology; based on events that occurred in the past, analyzed, and explained. The researchers also adopted the inductive and deductive methodologies.

\section{The Crisis of Arabization of the Term: Historical Background}

Any historical research in the crisis of Arabization of the term, must return to the moment that started rooting the term, particularly starting with Islam, affecting the displacement of the core issues in that culture, namely considering the system of Arab culture as based on two major pillars from Arabs and Muslims points of view: The Holy Quran and the (Hadith), which is like the recitals of their prophet. The Arabic language, in consequence, relying on its excellent network, worked hard, through its thinkers and linguists, to manage overcoming the state of instability in its concepts and terminology; and to build a new cultural system, where many words have acquired new meanings, and trying to introduce new words that established their deep meanings into the emerging conceptual map of both Arab linguists and thinkers. The most important factor in this rapid and remarkable achievement is the investment of the enormous potential of Islamic culture and its incubation of (Arabic language); this graphic culture in its essence, which only Arab thinkers consider its own proof, would not have been separated from its patriarchal mental system, based on its both linguistic and religious instruments, and therefore, affected by its ideological superiority criterion, but that became attached to the condition that cannot be tolerated in terms of their considered Islam as faith. In this context, the linguists worked only according to a strategy in which the term "faith" was their top priority, and the jurists also worked according to the strategy that represented the potential of the Arabic language as the top and most elite one, considering it as the language of Koran. And thus this leads to the linkage between both linguistic and ideological terms of unity affecting ideology, so that every ideological aspect became founded upon language, while both Islam as religion and Arabic as a language, acquired their historical and political depth rejecting others as right unless they resign to accept Islam as a doctrine, so that they clashed with the objective reality of other nations who differed from them in terms of both language, and religion, admitting that they differ from the first moment, connecting this clash with historical facts and events.

On the other hand, it is remarkable in influence by foreign and Greek cultures on the Arab culture, so that the Greek influence was the most exclusively influential on the Arab culture, and it is the most prominent affecting historical knowledge in the Arab culture. One can consider the crisis of Arabization of the term as limited in impact, according to the following reasons:

- The low number of Arab intellectuals who have studied the Greek culture.

- Some intellectuals who have studied the Greek culture focused on specific themes that fall within the category of "philosophy, logic and medicine", such as (Al-Farabi, Ibn Sina, Ibn Rushd).

- Some Arab intellectuals who contacted the Greek culture have a deep knowledge of the sciences of religion and Arabic language, which led them to benefit from (logic), such as (A-Shafei, Khalil bin Ahmed Al-Farahidi, Mu'tazilah).

- Some of the Arab intellectuals have completed translations of weak Greek versions of translations; either because some of them were either fluent in the Greek language or the Arabic language.

- The spread of the Arab political, ideological and linguistic system and its good status at the beginning of the Abbasid period, compared to the deterioration of the political, ideological and linguistic systems of other foreign cultures.

Based on the last reason, we can specifically say that the Arab intellectuals did not like to expose to the use of some foreign terms, that remained limited in use to elite issues, and it also did not prevent arabization, and therefore (dissolving) in the system of Arab culture. The different points of view of the Arab intellectuals in this regard can be summarized as follows: 
- Uncertain sufficiency, as represented in the work of Khalil bin Ahmed Al-Farahidi and other grammarians using the tools of Greek logic, escalating the role of measurement and induction.

- The complete rationality sufficiency, as reflected in the responses of Seraphee to Matthew Ben Younis in the famous debate, which was reported by Altawhidi in the "Entertainment" writings.

- The complete sufficiency in terms of the causative methodically, as represented in the opinion of Ibn Atheer in the books of Ibn Sina.

- Relative sufficiency, as represented in the book (Poetry Criticism) by Qudamah bin Jaafar, where he succeeded in choosing the appropriate Greek concept of the pattern of expression according to the rhetoric reflection of Arabs.

- Conceptual or conventional appropriation, as represented in the book (Proof) by Ibn Wahab.

- Arabization of the foreign term and making it (relative to the common) as represented in the letter (Approximation to Logic) by Ibn- Hazm.

- $\quad$ Reporting of the term and its history, as represented in the (Introduction) by Ibn Khaldun.

Ibn Khaldun's (Introduction) puts us at the end of a cultural context and the beginning of another cultural context that Ibn Khaldun expressed as a statement or a hint, as taking care for the term was in fact a reaction to the feeling of confusion that was manifested by the gradual divergence of the Islamic political systems following the Abbasid era of the Arabic language. Therefore, what has been achieved from the lexicons of terminology in such times did not really involve the absorption of the importance of the reformer's report, as much as it included a sense of the term and the aggravation of the crisis of the term.

The Ottoman Empire cannot be the only responsible of the decline of Arab civilization, and researchers do not believe that the policy of the Ottomans led to wasting the Arab intellectual balance of civilization and sense of linguistic competence even at the peak of the Ottoman Islamic cosmopolitan, so that the marginalization of the Arabic language and the marginalization of its cultural role have led the Arab intellectual to an enviable situation, so that the Arab intellectual belongs to an empire that derives its legitimacy from the Islamic ideology, but it leads to separation from the instrument of this legitimacy; which is the (Arabic language).

This situation took on a tragic trait when this empire deteriorated, and when the power of Napoleon Bonaparte targeted the minds of the Egyptians and the Arabs; who had lost faith in the religious and political legitimacy of the Ottoman Empire, and were almost withdrawn from their cultural and cognitive context in the Arabic language.

Arabs have entered the modern era, and the case turned upside down; they are politically defeated and linguistically expatriates, and accused by Ernest Renan and other orientalists, both religiously and culturally. (Renan, 1955)

The pioneers of the renaissance have tried to prevent the deepening rejection of other cultures and the deterioration of the Arab culture, considering the other cultures in terms of enmity, in the form of total or relative rejection of dealing with the other and advocating a fake sufficiency that was not supported by geo-politics as (Afghani, Muhammad Abdo) mentioned. Or reacting as being dazzled by the West and its liberal values and useful sciences and practical languages, calling for the exposition of history and language as (Farah Anton, Shibli Shamil, and Salama Musa) discussed.

\section{The Crisis of Arabization of the Term}

The case of the current Arab researchers in the the crisis of Arabization of the term, is confusing; as they have not yet achieved an up-to-date reading that can be relied upon in the field of the Arabic-Islamic term, nor has he been able to represent the Western term as a form in which we can feel stability and reassurance (Haeri, 2000).

The main reason that led the Arab researchers to this situation of confusion is the illusion of the ability to possess a term that can immediately replace the Western term directly or immediately when translated, in spite of the implications of this substitution, which is described by the fall of the Arab term automatically and that caused the creation of forced separation with the inherited on one hand, and the neglected of the context of knowledge and history, on the other hand, and that produced the Western term in consequence (Green, 2012).

It is certain that the future of the Arabic language, in light of the successive challenges of globalization and the clash of civilizations and struggle of languages, is bound by the degree of success that can be achieved in the Arabization of university education (Kumaravadivelu, 2008), and the extent of this success is also dependent on the degree of achievement that can be achieved in establishing and standardizing the term. This is what the 
Councils of the Arabic Language have sought to work on through a number of new lexicon projects discussed at the 10th Arabization Conference in Damascus, with a view to the adoption by the Arab League for Education, Culture and Science.

It is gratifying to note that the recommendations of the Scientific Advisory Council of the Coordinating Bureau for Arabization, which had been held in Morocco before, had risen to the level of the challenges faced by the Arabic language. It stressed the need to establish an information network aimed at linking the "terminology database" in the Arab Councils, as well as the establishment of a database of Arab experts and lexicographers and the continuation of the comprehensive automated lexicon project, which is expected to include all the standard terminology previously adopted by the Arabization conferences. However, our adherence to all these recommendations and assurances does not negate the need to regard the following achievements and perceptions:

- It is wrong to think that "Arabization" necessarily requires the rejection of foreign languages, for the simple reason that Arabization cannot be equated without the need to know the Arabic language in one hand, and to know the foreign languages on the other hand.

- It is also wrong to know that the knowledge of Arabic and foreign languages are all that we need in the process of Arabization, as there is a third urgent condition which is to know the functions and meanings of the translated context.

- It is also wrong to think that the process of Arabization can start automatically, even if we provide the three previous conditions, because there is a fourth condition; which is the need to adopt the translated context in the Arab culture system.

Therefore, it is not surprising that the Arabization process is proceeding slowly, and that we see this refusal to Arabization in the scientific, social, human and even literary circles in the Arab world.

There is a large gap between characterization in language and the absorption of the function or meaning when considering languages whether discussing the term in Arabic language or other foreign languages; as the question of Arabization and the meaning deserves the utmost attention, it should not be seen as a language fascism, as some proponents for the clash of civilizations or the clash of languages would say.

UNESCO takes care of the preservation and development of the living languages in general and the major languages of the world in particular, as it has assigned global day to celebrate the mother tongue. The most recent studies and statistics in the world indicate that the preservation, dissemination and development of the national languages came at the top of the list of its priorities and budgets of both large and small states. Therefore, we should point out that Ireland, although it is one of the poorest European countries, has established an Irish language agency, and spent a considerable cost to develop its language, and Indonesia has also designated October as a national month of the Indonesian language each year. Besides that the United States uses at least five international bodies to promote English, the British annual budget for developing the English language is (200 million $£$ ), while Spain allocated (75 million \$) for the development of the Spanish language (Coulmas, 2005).

\section{Arabic Language in Light of (Clash of Civilizations) Statement}

In the third chapter of his book "The Clash of Civilizations" Samuel Huntington declared that there is a universal civilization in light of the standards of modernization and Westernization, he also discussed language under a separate sub-title (Huntington, 1993). And in line with his firm belief that the world is a candidate for more polarization of civilization and not for further cultural breakthrough in general, and that the West is candidate for threats in particular, he spares no effort to undermine the reassurance that "English is the language of the world", stressing on the evidence that can be relied upon to deny this reassurance. According to this evidence proposed by the data presented by Professor Sidney Clbert (University of Washington) (1958-1992), Huntington shows that there is a significant decrease in the number of speakers in English, French, German, Russian and Japanese in the first place, and that this decrease corresponds to a significant increase in the number of speakers of Hindi, Malay, Arabic, Bengali, Spanish and Portuguese. Huntington concludes that the proportion of English speakers has dropped globally from $9.8 \%$ in 1958 to $7.6 \%$ in 1992, therefore English language that seems strange to $92 \%$ of the people in the world cannot be the language of the world, but It can be a means of communication between cultures because it has become "ethno-centric", but it will not be a source of social identity.

One may understand that Huntington is very concerned that Arabic language according to his statistics has recorded the highest rise in the proportion of speakers as a major language in the world, increasing from $2.7 \%$ in 
1958 to $3.5 \%$ in 1992 . This raised his frank concern to warn that the gradual deterioration of the West's influence on other civilizations will lead to a gradual decline in the use of English.

Huntington realized that the use of English in non-English speaking communities is growing among the elites of these communities for reasons dealing with their desire to distinguish themselves from the normal people of society and to facilitate their connection to the West, and it is also increasing at the university level to improve graduate students' chances of finding employment in the midst of global competition for human capital. However, he warns that increasing social and political pressures, increasing democratic institutions and the participation of ordinary people in these institutions often lead to the collapse of Western languages and the dominance of national languages.

The distribution of languages throughout the world and throughout history continues to reflect, according to Huntington, the distribution of global power. The most widely spoken languages such as (English, Mandarin, Spanish, French, Arabic, Russian) represented languages of (imperial states) that forced their people to use their own languages.

Thus, transformations in the distribution of global power usually lead to shifts in the use of languages, as Huntington asserted and confirmed the facts of civilized history, Arabic language will be targeted if we wish to express it in a pessimistic language or if we want to promote it, so that if we want to express an optimistic language, as a result reached in light of the conviction of the idea of the clash of civilizations in the West.

Whether we assume that the West will tend to assert its dominance over the Arab world, driven by its growing sense of power in general, or assume that it will tend to assert its dominance driven by its growing sense of fear that Chinese power will replace it in particular, or assume that the West will tend to assert its dominance driven by its growing sense of fear that Islamic power will replace it in particular, language will be one of the Western means of attack. In all these assumptions, the Arabic language will gradually be the most important means of defense and the most vulnerable to the laws of displacement.

\section{Arabic Language in Light of Globalization}

An expression such as the "global market dictatorship" may adequately provide the essence of globalization. But an expression like "a dictatorship with limited liability" seems more accurate in describing the essence and the disadvantages of globalization. Which is an expression used by Hans and Shamak in their famous book (The Trap of Globalization) to meet the two facets of globalization; on one hand, it has the least tolerance of the need to unify the world economy under one umbrella without national borders or identities and to remove any obstacle that may be hindered; a nation, a culture or a history. And on the other hand, it is not concerned with any political, economic, social or cultural effects that may arise as a result of its insistence on pursuing its inevitable path, as its advocates insist on so believing (Hans \& Schumack, 1998).

The book explains this paradox by saying: (These theorists have been the launchers of non-democratic, comprehensive and scientifically unjustified generalizations, such as saying: "Taking into account the social dimension and the needs of the poor has become an unbearable burden", and "the welfare state threatens the future, and that it was only a concession during the Cold War, or the claim that a certain amount of inequality is inevitable". The book makes it clearer in commenting on the similarities of the cosmopolitan village: Unlike the television that links people living in Africa, Asia and California, and unlike a few cities where modern industrial means and technologies are concentrated, they relate to each other and to the world more than to the countries to which they belong, the vast majority of the world turns, on the contrary, into separate islands, into a world of misery, crowded with poor cities.

Although Paul Hirst and Graham Thompson, in their book (Globalization: A Necessary Myth?), were not interested in harnessing the concept of globalization with less universal attention at all levels, but they emphasized the fact that the world is still far from being truly universe, because trade, investment and money flows are concentrated in the Tri-partite: Europe, Japan and North America, and this is what calls them to address the introduction of their book by the question (Globalization: A Necessary Myth?) (Hirst \& Thompson, 2010).

Regardless of the spread of globalization, making both the centers and parties as parallel, language is considered as the most dangerous and influential communication tool in the world markets, since it has a considerable qualitative weight in the economic thought to the extent that it is studied side by side with (cash flow) in the context of growth of national economies.

There are even those who look sadly at (the high price of multilingualism in the world) against the enormous profits that can be realized in light of the linguistic usage of only one language in world markets. It is obvious 
that the languages of the dominant centers of the world markets will take the interface of economic languages as long as the languages according to this criterion must be subject to a free market governed by the law of supply and demand and not according to the criterion of desire (Coulmas, 2005).

\section{The Arabic Language: The Failure to act in Reality and the Revival of the Future}

The most prominent Arab researchers identify the most common manifestations of Arab linguistic procrastination with the following features (Nabil, 2001):

First: Clear linguistic policies are still in drawers and not in action, they are far from actual implementation, while other countries spare no effort to prohibit the use of the foreign terms in their language daily usage.

Second: Arabic language communities are still to the elite, and its limited impact and weak financial potential, makes it unable to address what is really needed for developing the Arabic language, in addition to its reluctance to keep away from the developments of information age.

Third: Limiting the Arabic language to certain strategies and approaches of teaching methods and curricula, being restricted only to the Arabic language, rather than engaging it with other disciplines and laguages.

Fourth: Arabization has been severely opposed by many academics and intellectuals.

Fifth: The poor usage of the linguistic lexicon, particularly among intellectuals and writers.

The future of Arabic language is linked to change the stereotype mentality of both the teacher and student of Arabic language, and no matter how we have raised the level of our prospects and awakening of the Arabic language, so that the problem reveals itself in the collapse of the character and the deterioration in the role of the teacher and the student of the Arabic language. Therefore the basis for saving the language is by rehabilitating the personality of the teacher and the Arabic language speaker, as follows:

First: Attracting students with high grades who have the passion to study Arabic language, making it as their choice.

Second: Directing the Arabic language curricula so as to be more communicative in function, supplying the Arabic language with contemporary and practical features, preventing it from being accused of indoctrination and excess rhetoric.

Third: Linking the teaching of Arabic language to other branches of contemporary of knowledge and science, such as mathematics and computer, producing a generation of contemporary teachers.

Fourth: Recommending that the Arabic language students may work in various sectors other than teaching, such as language editing, press editing, translation, public relations, tourism, and diplomacy.

Fifth: Providing the students of the Arabic language with a high intellectual contemporary culture in order to expand their horizons and their ability to discuss and analyze the issues of their age, enabling their full expression in sound language.

\section{Conclusion}

It is noted historically that a quite clear clash was raised in Arabic literature when using Arabic language, that is manifested based on the problematic situation Arabs are living nowadays because of their inability to cope with globalization and issues caused by clash of civilizations.

\section{References}

Al-Jabri, M. A. (1985). The Formation of the Arab Mind, Dar al-Tali'ah (2nd ed.). Beirut.

Coulmas, F. (2005). Changing language regimes in globalizing environments. International Journal of the Sociology of Language, (175-176), 3-15. https://doi.org/10.1515/ijsl.2005.2005.175-176.3

Green, N. (2012). Sufism: A global history (Vol. 34). New York: John Wiley \& Sons.

Haeri, N. (2000). Form and ideology: Arabic sociolinguistics and beyond. Annual Review of Anthropology, 29(1), 61-87. https://doi.org/10.1146/annurev.anthro.29.1.61

Hans, R. M., \& Harald, S. (1998). The Trap of Globalization. Translated by Adnan Abbas Ali. Knowledge World Series, Kuwait.

Hirst, P., \& Thompson, G. (2010). Globalization: A Necessary Myth? Globalization: the Greatest Hits (pp. 71-84). Boulder, Colorado: Paradigm Publishers.

Huntington, S. P. (1993). The clash of civilizations? Foreign Affairs, 22-49. https://doi.org/10.2307/20045621 
Kumaravadivelu, B. (2008). Cultural globalization and language education. New Haven, Connecticut: Yale University Press.

Nabil, A. (2001). Arab Culture and the Information Age, The World of Knowledge Series, II, Kuwait.

Renan, E. (1955). The Meaning of Nationality. Nationalism. H. Kohn (Ed.). Princeton: D. Van Nostrand.

Rozental, M. M., \& Yudin, P. (1985). Philosophical Encyclopedia. Translated by Samir Karam \& Dar Taliaa, 5, Beirut.

Selsam, H., Rosenthal, M., \& Yudin, P. (1950). Handbook of philosophy.

Spolsky, B. (2009). Language management. New York, NY: Cambridge University Press. https://doi.org/10.1017/CBO9780511626470

Stadlbauer, S. (2010). Language ideologies in the Arabic Digossia of Egypt. Colorado Research in Linguistics, $22,1-19$.

Von Herder, J. G. (2002). Herder: Philosophical Writings. Cambridge: Cambridge University Press. https://doi.org/10.1017/CBO9781139164634

Zakaria, F. (2011). The post-American world: Release 2.0. New York, NY: W. W. Norton Company.

\section{Copyrights}

Copyright for this article is retained by the author(s), with first publication rights granted to the journal.

This is an open-access article distributed under the terms and conditions of the Creative Commons Attribution license (http://creativecommons.org/licenses/by/4.0/). 